\title{
Cortical Areas Involved in Horizontal OKN in Cats: Metabolic Activity
}

\author{
Susan J. Herdman, ${ }^{1}$ Ronald J. Tusa, ${ }^{2}$ and Carolyn B. Smith ${ }^{3}$ \\ 'Department of Otolaryngology-Head and Neck Surgery, and 'Department of Neurology, Johns Hopkins Hospital, \\ Baltimore, Maryland 21205, and 'Laboratory of Cerebral Metabolism, National Institute of Mental Health, Bethesda, \\ Maryland 20892
}

Cerebral cortex improves optokinetic responses to high target velocities, but the specific cortical areas involved are unknown. Using the ${ }^{14} \mathrm{C}$-deoxyglucose technique, we compared local rates of cerebral glucose utilization in cats viewing a moving optokinetic nystagmus (OKN) drum (experimental group) with those in cats viewing a stationary OKN drum (control group). In the experimental group, glucose utllization was increased in areas 17 and 18 and in 4 areas in suprasylvian cortex (21a, 21b, PMLS, and VLS). There were no changes in glucose utilization in areas $7,19,20 \mathrm{a}$, 20b, ALLS, AMLS, DLS, PLLS, the posterior suprasylvian area, and the splenial visual area.

The increases in glucose utilization in areas 17 and 18 were most significant in the granular layers (inner III and IV). In areas $21 \mathrm{a}, 21 \mathrm{~b}$, PMLS, and VLS, the increases in glucose utilization extended from layers II through $\mathbf{V}$. There was also a regional distribution of the increase in glucose utilization within each of these areas in the experimental animals. The increase in glucose utilization did not include the rostral portion of PMLS or the borders between areas PMLS and $21 \mathrm{a}$, and VLS and $\mathbf{2 1 \mathrm { b }}$. In addition, there was a smaller increase in glucose utilization at the borders between areas 17 and 18 than in other portions of these 2 areas.

The results indicate that areas 17, 18, 21a, 21b, PMLS, and VLS may be involved in the cortical modulation of horizontal OKN. The laminar distribution of label within the cortical areas corresponds with the distribution of projections from the dorsal lateral geniculate nucleus to areas 17 and 18, and from areas 17 and 18 to PMLS. The regional distribution of the metabolic activity within areas 17, 18, and PMLS coincides with that portion of cortex expected to be excited by either the spatial frequency of the stimulus or the retinalslip velocity (drum velocity minus slow phase eye velocity) occurring during the eye movements.

In the cat, cerebral cortex improves optokinetic responses at high stimulus velocities (Montarolo et al., 1981; Hoffmann, 1982; Strong et al., 1984; Ventre, 1985). Extensive unilateral ablation of suprasylvian cortex involving areas PMLS, PLLS,

\footnotetext{
Received Feb. 10, 1988; revised June 27, 1988; accepted Sept. 8, 1988.

This work was supported by the Foundation for Physical Therapy and the Wilmer Core Grant EY-01765. We wish to thank Drs. James M. Sprague, Gary Rubin, and Louis Sokoloff and Alison Tannenbaum, J. D. Brown, and Jane Jehle for their thoughtful assistance.

Correspondence should be addressed to Susan J. Herdman, Ph.D., Department of Otolaryngology-Head and Neck Surgery, Carnegie 485, Johns Hopkins Hospital, 600 N. Wolfe Street, Baltimore, MD 21205.
}

Copyright (C) 1989 Society for Neuroscience $0270-6474 / 89 / 041150-13 \$ 02.00 / 0$
AMLS, ALLS, DLS, VLS, and 7, or bilateral lesions of areas 17-19 decreases the velocity of slow phase eye movements of optokinetic nystagmus (OKN) (Montarolo et al., 1981; Ventre, 1985). In addition, areas PMLS, AMLS, 21a, 21 b, 17, and 18 project to subcortical structures (the nucleus of the optic tract and the dorsal terminal nucleus) involved in the generation of OKN (Berson and Graybiel, 1980; Schoppmann, 1981; Marcotte and Updyke, 1982).

The purpose of this study was to further define the specific cortical areas involved in OKN. We used the quantitative ${ }^{14} \mathrm{C}$ deoxyglucose technique to measure local rates of cerebral glucose utilization in cats during the generation of an optokinetic response. These results were compared with values obtained from cats viewing a stationary OKN drum. Previous studies have evaluated the metabolic activity of cat visual cortex using the 2-deoxyglucose technique, but these studies were strictly qualitativc and cxamined only cortical areas 17-19 (Albus, 1979; Flood and Coleman, 1979; Lang and Henn, 1980; Schoppmann and Stryker, 1981; Singer, 1981; Tootell et al., 1981; Wagner et al., 1981; Thompson et al., 1983; Albus and Sieber, 1984; Lowel et al., 1987). In our study, we have quantitatively examined the metabolic activity of all known cortical visual areas lying within occipital, temporal, and parietal cortex in awake behaving cats viewing an OKN drum. We found that only 6 regions of cortex-corresponding to areas $17,18,21 \mathrm{a}, 21 \mathrm{~b}$, PMLS, and VLS-had an increase in glucose utilization in cats generating horizontal OKN.

In the second paper we will describe the effects of unilateral ablation of areas 17, 18, 21a, 21b, PMLS, and VLS on OKN, VOR, and VOR gain plasticity (Tusa et al., 1989).

Preliminary reports of this research have been presented elsewhere (Herdman and Tusa, 1984, 1986).

\section{Materials and Methods}

General experimental procedures. Nine adult, male cats $(3.5-4.5 \mathrm{~kg})$ were used in this study. Plexiglas head holders and eye coils were implanted under sterile conditions while the animals were anesthetized with intravenously administered sodium pentobarbital. The cats were treated postoperatively with ophthalmic ointment and penicillin administered intramuscularly for 1 week. Five days after surgery, oculomotor responses were tested in each cat using the magnetic-field search coil technique (Robinson, 1963). This recording system has a resolution of $1.5 \mathrm{~min}$ of arc and is linear within a $40^{\circ}$ range with an error of less than $6 \%$. The head holder was used to immobilize the cat's head so that the eyes were level with the horizon. Awake cats were restrained by placing their bodies in a canvas bag inside a loose-fitting box to which their head plates were bolted. The eye movement recording system was calibrated by rotating the magnetic field coils around the stationary cat at a known speed (Robinson, 1976). Measurements for calibration were taken during moments of steady eye fixation.

In the experimental group, OKN responses were elicited by rotating 
a full-field drum around the cat's head. The stimulus was a full-field OKN drum that contained a random pattern of black circles that subtended a visual angle of $8^{\circ}-16^{\circ}$ against a white background. A 2-dimensional FFT of the image was computed using Fourier Prospective II for the IBM PC (Alligator Transforms, Costa Mesa, CA). The bandwidths were then computed on the basis of a horizontal slice through the origin of the 2-dimensional FFT. The stimulus had a contrast that approached 1 and a spatial frequency at half-maximum amplitude of 0.125 cycles $/ \mathrm{deg}$ and at $1 / 10$ th maximum amplitude of $0.38 \mathrm{cycles} / \mathrm{deg}$. The steady-state optokinetic slow phase eye velocities at drum speeds ranging from $5^{\circ}$ to $120 \% \mathrm{sec}$ (accelerated at $0.15 \% \mathrm{sec} / \mathrm{sec}$ ) were determined for each cat. The drum velocity that elicited the maximum slow phase eye velocity of OKN during binocular viewing was then used during the deoxyglucose experiment. During the deoxyglucose experiment, the OKN drum was rotated at a constant velocity in a clockwise direction only. The mean drum velocity used was $45 \% \mathrm{sec}$.

In the control group, the cats viewed the same OKN drum, but the drum was held stationary. Spontaneous saccades were monitored during the deoxyglucose experiment for later calculation of the frequency, retinal slip velocity, and direction of saccades. The ambient lighting was the same for both the experimental and the control groups.

Determination of local rates of cerebral glucose utilization. Local rates of cerebral glucose utilization were determined by means of the autoradiographic ${ }^{14} \mathrm{C}$-deoxyglucose method in 3 control and 4 experimental cats (Sokoloff et al., 1977). In 2 other cats the deoxyglucose technique was used, but the results were not quantitated. The results from these 2 cats were used for mapping purposes only. While the cats were anesthetized with halothane and nitrous oxide gas, polyethylene catheters were inserted into one femoral artery and vein. The free ends of both catheters were tunneled subcutaneously from the groin to a subcutaneous pocket in the animal's back. The tissues around the incisions were infiltrated with a long-acting topical anesthetic ( $2 \%$ marcaine with epinephrine, $6 \mathrm{hr}$ effective duration). In addition, pledgets soaked with the anesthetic were placed in the incision. The incisions were closed and the general anesthesia stopped. The animals were then returned to their home cages and allowed to recover from the anesthesia for $3 \mathrm{hr}$. At the end of this time the topical anesthetics were reapplied, and the free ends of the catheters were removed from the subcutaneous pocket. The animals were then positioned in the OKN drum.

To eliminate the novelty effect of the stimulus (Hand, 1981), the cats viewed rotating OKN drum (experimental group) or a stationary drum (control group) for $5 \mathrm{~min}$ before the injection of the deoxyglucose. A pulse of 2 -deoxy-D-14 $\mathrm{C}$-glucose $(100 \mu \mathrm{Ci} / \mathrm{kg}$ body weight; specific activity, $50-56 \mathrm{mCi} / \mathrm{mmol}$, New England Nuclear) contained in $1 \mathrm{ml}$ of normal saline was injected intravenously and the animals were stimulated for $45 \mathrm{~min}$. Decreases in slow-phase eye velocity in the experimental cats or decreases in the frequency of spontaneous saccades in the control cats were used as an indicator that the animal's alertness was decreasing. Novel auditory stimuli were used to help maintain the animal's alertness. Plasma glucose and deoxyglucose concentrations were determined in arterial blood samples taken sequentially during the experiment. At the end of the $45 \mathrm{~min}$ period, the cats were injected intravenously with a lethal dose $(50 \mathrm{mg} / \mathrm{kg}$ body weight) of sodium pentobarbital and then perfused for $1 \mathrm{~min}$ with normal saline followed by perfusion for $1 \mathrm{~min}$ with $3.3 \%$ formalin (phosphate buffered, $\mathrm{pH} 7.4$ ). This perfusion procedure does not alter the quantitative aspects of the labeling (Hand, 1981). The brain was then blocked in a stereotaxic apparatus. Each block of tissue was frozen in isopentane chilled to $-40^{\circ} \mathrm{C}$ with dry ice and was stored at $-70^{\circ} \mathrm{C}$. Coronal sections, $20 \mu \mathrm{m}$ thick, were cut in a cryostat maintained at $-18^{\circ} \mathrm{C}$. Every 5 th section was picked up on a gelatin-coated slide and immediately dried on a hot plate heated to $60^{\circ} \mathrm{C}$. The tissue sections, along with calibrated ${ }^{14} \mathrm{C}$ methylmethacrylate standards were then placed in $\mathrm{X}$-ray cassettes and autoradiographs were prepared on SB5 film (Kodak) (Sokoloff et al., 1977). After development of the autoradiographs, the tissue sections were stained with thionine for histological examination.

Autoradiographs were scanned and digitized with a Photoscan System P-1000 densitometer (Optronics International, Chelmsford, MA) (Goochee et al., 1980). Rates of glucose utilization were determined as described previously (Sokoloff et al., 1977). A value of 0.411 was used as the lumped constant (Sokoloff, 1982). The cytoarchitectural boundaries and laminae of areas 17-19 were based on the histological descriptions of Otsuka and Hassler (1962). The locations of the other visual cortical areas $(7,20 \mathrm{a}, 20 \mathrm{~b}, 21 \mathrm{a}, 21 \mathrm{~b}$, PMLS, PLLS, AMLS, ALLS, DLS, VLS, PS, and SVA) were based on the maps of Tusa et al. (1978, 1979), Tusa and Palmer (1980), Palmer et al. (1978), and Rosenquist (1985).
For each cortical area, rates of glucose utilization were determined within a representative portion of cortex extending from the top of layer I to the junction of the gray and white matter. For each cortical area, measurements were repeated through a series of 6-25 coronal sections depending on the extent of the area. One reading was made for each area in each section. The local rates of glucose utilization in the supragranular (II, outer III), infragranular (V, VI), and granular (inner III, IV) layers for areas 17 and 18 were also determined. Analysis of the distribution of label by individual layers in areas 17 and 18 was not possible because the resolution of the quantitative ${ }^{14} \mathrm{C}$-deoxyglucose technique is limited to $200 \mu \mathrm{m}$ (Smith, 1983).

Statistical analysis. Each cortical area in the experimental cats and in the control cats was analyzed for differences in rates of glucose utilization between the right and the left hemispheres with a paired $t$ test. Because several cortical areas were measured in each animal, the Bonferroni correction for multiple comparisons was applied (Miller, 1966). Each cortical area was also analyzed for statistically significant differences in rates of glucose utilization between the experimental and the control groups with the Student's $t$ test and the Bonferroni correction.

Preparation of cortical flat maps. The locations of the label in the digitized autoradiographs were fitted onto a 2-dimensional reconstruction of cat cortex according to the techniques of Van Essen and Maunsell (1980) and Ungerleider and Desimone (1986). This was done by photographing autoradiographs of coronal sections spaced every $1-2 \mathrm{~mm}$. A wire outline of each photographed coronal section was then made. On each wire outline we marked the location of regions with a statistically significant increase in metabolic activity, the sulci and the lips of the fundi. The wire outlines were then soldered onto orthogonal wires with the appropriate spacing maintained between each section. This 3-dimensional model of the cat brain was then flattened into a 2-dimensional map. In order to do this, the model was cut on the medial surface along a horizontal line from the splenium of the corpus callosum to the occipital pole. In some cats, additional cuts had to be made near the anterior ectosylvian sulcus. In order to determine to what extent the regions of increased glucose utilization correspond with visual cortical areas defined electrophysiologically, a 2-dimensional reconstruction was also made of the published electrophysiological maps of cat cerebral cortex (Tusa et al., 1981).

\section{Results}

\section{Eye velocity}

In the experimental cats, the mean slow-phase eye velocity was $16.4 \pm 2.2 \%$ sec (mean $\pm \mathrm{SD}$ ) and the mean retinal-slip velocity (drum velocity minus eye velocity) for slow phase eye movements was $29.5 \pm 5.0 \% \mathrm{sec}$. The mean retinal-slip velocity during quick-phase eye movements was $98.7 \pm 20.6 \%$ sec. All experimental cats made slow phase optokinetic eye movements for the entire 45 min deoxyglucose experiment. In the control cats, the mcan retinal-slip vclocity during spontancous saccades was $55.9 \pm 8.7 \% \mathrm{sec}$, and the same number of saccades were made in both directions. The frequency of saccades in the control cats was $1 / 20$ the frequency of the quick phases made by the cats in the experimental group.

\section{Local rates of glucose utilization}

Rates of glucose utilization were determined in 20 cortical regions in 4 experimental and 3 control cats. When interhemispheric comparisons were made, only area PMLS in the control animals showed a statistically significant difference $(p<0.05$, paired $t$ test) (Table 1). In the supragranular layers of area 17 and in area $20 \mathrm{~b}$ in the control cats and in the granular layers of area 17 in the experimental cats, the differences between the 2 sides approached statistical significance $(p<0.1)$. In all cases, the differences between the 2 sides were less than $6.6 \%$. This percentage difference is within the inherent error of the deoxyglucose technique, which can be as high as 10-15\% (L. Sokoloff, personal communication). Additionally, when the Bonferroni correction for multiple comparisons was applied, none of the side-to-side differences were significant. Because of the low per- 


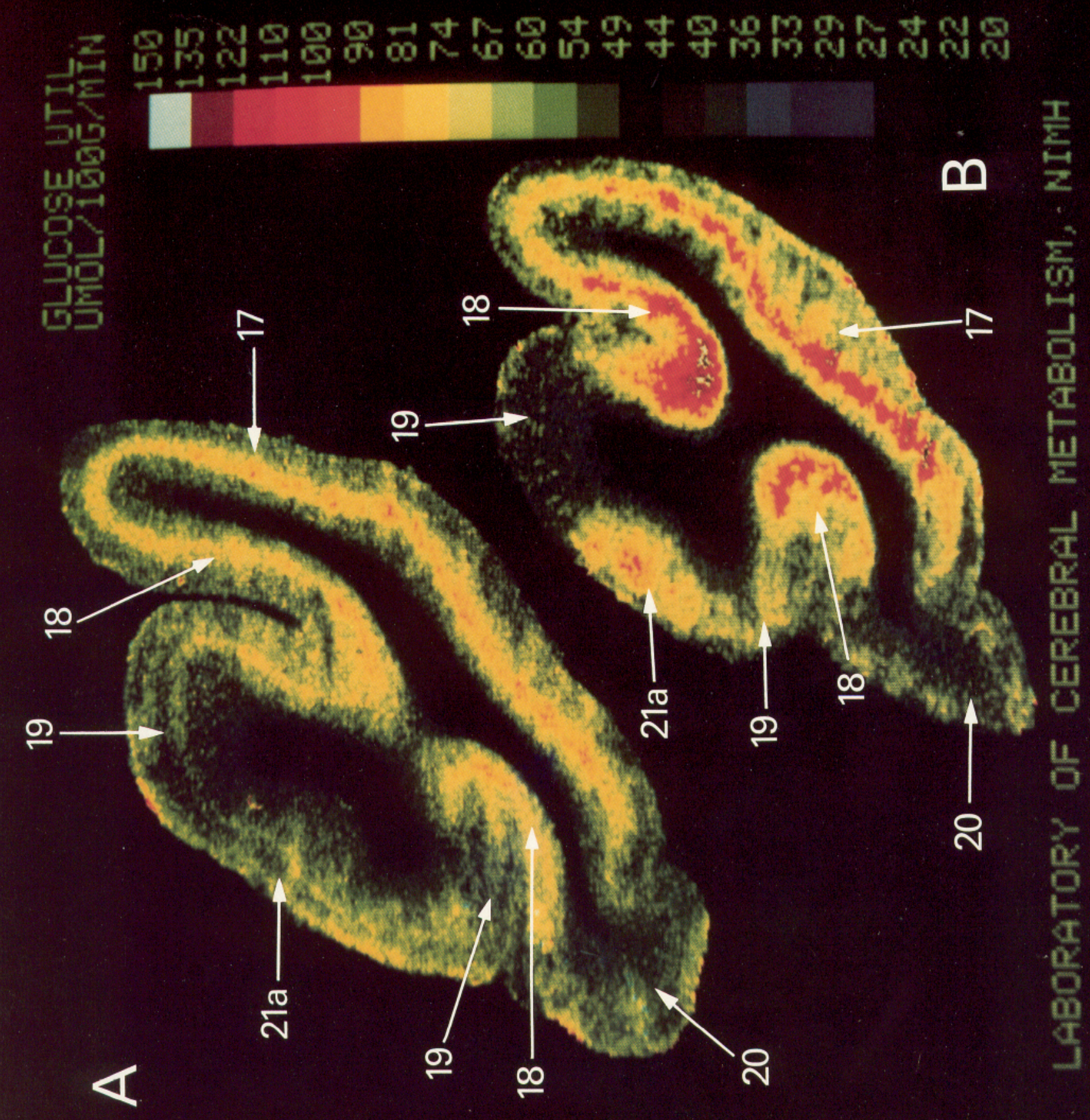


centage difference, as well as the results of the statistical analyses, side-to-side differences were not considered further, and the means of the left and right values from each animal were averaged.

When the metabolic activity of the areas in the experimental group was compared with the metabolic activity of the areas in the control group (Table 2), the granular layers of areas 17 and 18 , the infragranular layers of area 18, and areas PMLS, $21 \mathrm{~b}$, and $21 \mathrm{a}$ had a significant increase in the rates of glucose utilization in the experimental group compared with the control group ( $p<0.05$, Student's $t$ test). The differences between the 2 groups for each area ranged from 13 to $36 \%$. There was also an increase in glucose utilization in area VLS and in the infragranular layers of area 17 in the experimental group compared with control group that approached statistical significance $(p<$ 0.09 ) and that represented a $12-22 \%$ difference between the 2 groups. For area PS, there was a large percentage difference $(18 \%)$ between the experimental and the control group, but this difference did not approach statistical significance $(p<0.26)$. In areas 20b, 20a, ALLS, SVA, AMLS, 19, 7, DLS, PLLS, and the supragranular layers of areas 17 and 18 , no statistically significant differences were found between the experimental and the control groups $(p>0.20)$ and the percentage differences were small. When the Bonferroni correction for multiple comparisons was applied, only the increase in glucose utilization in the granular layers of areas 17 and 18 was statistically significant. With the Bonferroni correction for multiple comparisons, a 0.05 level of significance is reached at a $p$ value that is less than 0.0025 .

Representative autoradiographs prepared from brain sections from a cat in the control group (Fig. $1 \mathrm{~A}$ ) and from a cat in the experimental group (Fig. $1 B$ ) taken at a comparable level are shown in Figure 1. In the control cat, the label was distributed primarily in the cortical mantle in areas 17 and 18. Based on a comparison of the autoradiograph with the thionine stain of the same tissue section, this label was located in the granular layers (inner portion of III, and layer IV) of cortex. In the experimental cat (Fig. $1 B$ ), there was an increase in glucose utilization in the granular and infragranular layers of areas 17 and 18 and there werc also increases in glucose utilization in 4 arcas in suprasylvian cortex, one of which (area 21 a) is shown in this figure. Based on a comparison of the autoradiographs to the thionine stain of the same tissue sections, the increase in glucose utilization in the suprasylvian areas extended through layers II-V.

\section{Regional distribution of glucose utilization in cortical areas}

Portions of the 6 cortical areas in an experimental cat that had an increase in glucose utilization are illustrated in Figure 2. The boundaries of areas 17 and 18 on the line drawings were based on thionine-stained tissue sections (Otsuka and Hassler, 1962). The boundaries of the other cortical areas on the line drawings were based on published electrophysiological mapping studies
Table 1. Interhemispheric comparison of local rates of glucose utilization

\begin{tabular}{|c|c|c|c|c|}
\hline \multirow[b]{2}{*}{ Cortical area } & \multicolumn{2}{|c|}{$\begin{array}{l}\text { Glucose utilization } \\
(\mu \mathrm{mol} / 100 \mathrm{gm} / \mathrm{min})\end{array}$} & \multirow[b]{2}{*}{$p$} & \multirow{2}{*}{$\begin{array}{l}\text { Differ- } \\
\text { ence } \\
(\%)\end{array}$} \\
\hline & Left & Right & & \\
\hline \multicolumn{5}{|c|}{ Control animals $(n=3)$} \\
\hline 17 infragranular & $54.6 \pm 3.1$ & $53.7 \pm 2.7$ & 0.61 & 1.7 \\
\hline 17 granular & $70.4 \pm 1.9$ & $69.9 \pm 2.8$ & 0.76 & 0.7 \\
\hline 17 supragranular & $51.7 \pm 1.8$ & $53.3 \pm 2.0$ & 0.06 & 3.1 \\
\hline 18 infragranular & $52.3 \pm 2.2$ & $55.2 \pm 3.1$ & 0.23 & 5.5 \\
\hline 18 granular & $68.8 \pm 1.9$ & $69.1 \pm 4.5$ & 0.91 & 0.4 \\
\hline 18 supragranular & $53.8 \pm 1.6$ & $54.6 \pm 2.0$ & 0.22 & 1.5 \\
\hline 7 & $42.1 \pm 3.1$ & $41.8 \pm 2.8$ & 0.79 & 0.7 \\
\hline 19 & $47.6 \pm 1.7$ & $46.9 \pm 2.2$ & 0.64 & 1.5 \\
\hline $20 \mathrm{a}$ & $46.2 \pm 2.6$ & $44.3 \pm 2.7$ & 0.24 & 4.3 \\
\hline $20 \mathrm{~b}$ & $42.6 \pm 2.0$ & $40.1 \pm 2.8$ & 0.09 & 6.2 \\
\hline SVA & $50.7 \pm 2.8$ & $49.9 \pm 3.4$ & 0.46 & 1.6 \\
\hline $21 \mathrm{a}$ & $54.8 \pm 2.6^{\alpha}$ & $54.2 \pm 2.5$ & 0.14 & 1.1 \\
\hline $21 b$ & $51.7 \pm 2.0$ & $51.6 \pm 2.3$ & 0.98 & 0.2 \\
\hline ALLS & $50.2 \pm 1.0$ & $53.5 \pm 3.5$ & 0.60 & 6.6 \\
\hline AMLS & $51.7 \pm 1.8$ & $50.0 \pm 1.0$ & 0.47 & 3.4 \\
\hline PLLS & $45.8 \pm 6.2$ & $47.2 \pm 3.2$ & 0.72 & 3.1 \\
\hline PMLS & $54.7 \pm 1.9$ & $53.5 \pm 2.1$ & 0.02 & 2.2 \\
\hline PS & $42.8 \pm 2.2$ & $43.8 \pm 4.2$ & 0.79 & 2.3 \\
\hline VLS & $54.0 \pm 3.2$ & $53.8 \pm 3.0$ & 0.74 & 0.4 \\
\hline DLS & $46.5 \pm 1.8$ & $48.4 \pm 1.8$ & 0.52 & 4.1 \\
\hline \multicolumn{5}{|c|}{ Experimental animals $(n=4)$} \\
\hline 17 infragranular & $61.5 \pm 1.5$ & $59.4 \pm 1.9$ & 0.14 & 3.5 \\
\hline 17 granular & $91.1 \perp 1.3$ & $88.6 \perp 1.8$ & 0.09 & 2.8 \\
\hline 17 supragranular & $56.5 \pm 2.9$ & $57.6 \pm 1.9$ & 0.63 & 1.9 \\
\hline 18 infragranular & $61.2 \pm 1.1$ & $60.6 \pm 2.0$ & 0.66 & 1.0 \\
\hline 18 granular & $93.8 \pm 1.6$ & $93.8 \pm 1.6$ & 1.0 & 0.0 \\
\hline 18 supragranular & $56.6 \pm 4.3$ & $56.8 \pm 4.3$ & 0.93 & 0.4 \\
\hline 7 & $46.6 \pm 14.6^{a}$ & $46.2 \pm 16.5$ & 1.0 & 0.9 \\
\hline 19 & $48.3 \pm 4.2$ & $49.3 \pm 3.2$ & 0.77 & 2.0 \\
\hline $20 \mathrm{a}$ & $39.4 \pm 4.1$ & $41.3 \pm 3.8$ & 0.43 & 4.8 \\
\hline $20 \mathrm{~b}$ & $37.3 \pm 3.2$ & $36.2 \pm 3.5$ & 0.39 & 3.0 \\
\hline SVA & $46.0 \pm 4.4^{b}$ & $46.9 \pm 4.1$ & 0.40 & 2.0 \\
\hline $21 \mathrm{a}$ & $68.8 \pm 3.0$ & $66.8 \pm 3.4$ & 0.18 & 2.9 \\
\hline $21 \mathrm{~b}$ & $63.2 \pm 3.4$ & $64.6 \pm 2.3$ & 0.61 & 2.2 \\
\hline ALLS & $49.1 \pm 4.0$ & $50.6 \pm 2.8$ & 0.42 & 3.0 \\
\hline AMLS & $52.1 \pm 2.5$ & $53.1 \pm 2.8$ & 0.50 & 1.9 \\
\hline PLLS & $47.2 \pm 5.8$ & $46.5 \pm 4.0$ & 0.21 & 1.5 \\
\hline PMLS & $66.3 \pm 2.4$ & $68.9 \pm 3.8$ & 0.31 & 3.9 \\
\hline PS & $50.8 \pm 4.9^{b}$ & $51.2 \pm 5.2$ & 0.34 & 0.8 \\
\hline VLS & $65.1 \pm 4.3$ & $66.4 \pm 4.0$ & 0.68 & 2.0 \\
\hline DLS & $46.4 \pm 4.9$ & $47.8 \pm 4.5$ & 0.51 & 3.0 \\
\hline
\end{tabular}

Values for glucose utilization are the means \pm SE. The number of animals in each group is listed in the parentheses. Side-to-side comparisons were carried out separately for the experimental and the control groups. Data were analyzed for statistical significance by means of a paired $t$ test. Side-to-side differences for each area are also given as percentages.

${ }^{a} n=2 ; " n=3$.

Figure 1. Representative autoradiograph from a cat in the control group $(A)$ and a cat in the experimental group $(B)$ taken at comparable levels. These autoradiographs have been digitized with an image-processing system and color-coded for local rates of glucose utilization. The color bar provides a scale that indicates actual rates of glucose utilization (in $\mu \mathrm{mol}$ glucose $/ 100 \mathrm{gm}$ tissue/min), with white indicating the highest level of utilization. In the control animal $(A)$, the label was distributed in the middle of the cortical mantle in areas 17 and 18 . In the experimental cat $(B)$, there was an increase in the rate of glucose utilization in the granular and infragranular layers in areas 17 and 18 and in 4 suprasylvian areas, one of which is shown in here (21a). 

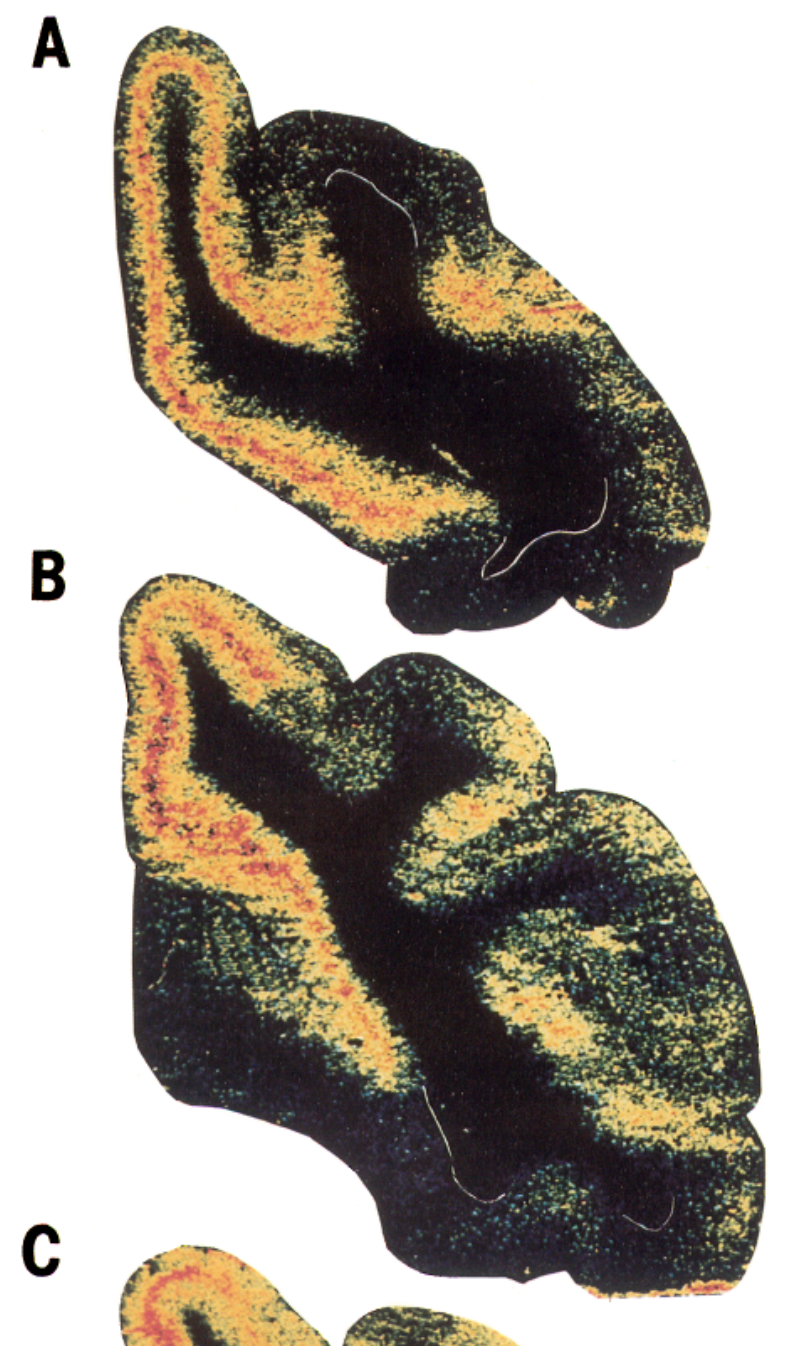
(Tusa et al., 1981). All of the regions with relatively high metabolic activity within cerebral cortex (as indicated by the red color) lie within areas 17, 18, 21a, 21b, PMLS, and VLS or within a region that corresponds with auditory cortex $(\mathrm{Au})$ (Reale and Imig, 1980). There was no evidence of a columnar organization in the distribution of the label within the 6 visual areas. Within each of these cortical areas in the experimental cats there appeared to be a regional distribution in the metabolic activity. The increase in the rate of glucose utilization did not include the portion of PMLS in the fundus of the suprasylvian sulcus (Fig. 2, $B, C$ ) nor the borders between areas 21a and PMLS, or between areas VLS and $21 \mathrm{~b}$ (Fig. $2 B$ ). A relatively smaller increase in metabolic activity, compared with the rest of areas 17 and 18 , occurred at the border between areas 17 and 18 . This is more clearly illustrated in the enlarged section in Figure 3. No regional distribution of metabolic activity was noted in the control cats.

Figure 3 shows enlarged views of digitized autoradiographs at the $17 / 18$ border and the $18 / 19$ border from an experimental cat along with the same sections stained with thionine. The rate of glucose utilization was relatively less within the portion of area 17 adjacent to the $17 / 18$ border (Fig. $3 B$ ). 'This portion of cortex with a lower rate of glucose utilization overlaps the histological transition zonc (Humphrcy ct al., 1985a) at the 17/18 border and extends into area 17. This relative decrease in glucose utilization extended along the entire rostrocaudal length of the $17 / 18$ border, although it was most obvious from Horsley-Clarke $\mathrm{P} 1-\mathrm{P} 4$, which is at or near the representation of area centralis in most cats (Tusa et al., 1978). There is also a histological transition zone between areas 18 and 19 (Humphrey et al., 1985b). Glucose utilization decreases at the beginning of this transition zone within area 18 and decreases further at the end of transition zone in area 19 (Fig. 3D).

\section{Two-dimensional reconstructions}

Two-dimensional reconstructions of cerebral cortex from 2 representative cats from the experimental group are shown in Figure $4, A, B$. The regions in which metabolic activity was higher in the experimental cats compared with the control cats are shaded. The borders of the regions of high metabolic activity were marked based on large $(>15 \%)$ decreases in metabolic activity compared with the adjacent cortex. In each of the 2-dimensional reconstructions, the caudal portion of the cerebral hemisphere is to the left, the most rostral section is to the right, the corpus callosum (CC) is at the top, and entorhinal (Erh) and paramygdala (Pam) cortices are at the bottom of the figure. The thin solid lines indicate the contour lines of each coronal section. The thick solid lines indicate the lips of each sulcus, and the dashed lines indicate the fundus of each sulcus. The reconstructions in Figure 4, $A, B$, should be compared with the 2-dimensional reconstruction of the electrophysiological maps of Tusa et al. (1981) shown in Figure $4 C$. The region "a" in the maps of metabolic activity (Fig. 4, $A, B$ ) corresponds to areas 17 and 18 (Fig. $4 C$ ), while regions "b, c, d, and e" roughly lie within areas $21 \mathrm{a}$, PMLS, 21b, and VLS. The same number
Table 2. Comparison of local rates of glucose utilization between control and experimental cats

\begin{tabular}{|c|c|c|c|c|}
\hline \multirow[b]{2}{*}{ Cortical area } & \multicolumn{2}{|c|}{$\begin{array}{l}\text { Glucose utilization } \\
(\mu \mathrm{mol} / 100 \mathrm{gm} / \mathrm{min})\end{array}$} & \multirow[b]{2}{*}{$p$} & \multirow{2}{*}{$\begin{array}{l}\text { Differ- } \\
\text { ence } \\
(\%)\end{array}$} \\
\hline & $\begin{array}{l}\text { Control } \\
(n=3)\end{array}$ & $\begin{array}{l}\text { Experimental } \\
\quad(n=4)\end{array}$ & & \\
\hline 18 granular & $68.9 \perp 3.2$ & $93.8 \perp 1.2$ & 0.0004 & +36 \\
\hline 17 granular & $70.1 \pm 2.3$ & $89.8 \pm 1.5$ & 0.0007 & +28 \\
\hline PMLS & $54.1 \pm 2.0$ & $67.6 \pm 3.0$ & 0.018 & +25 \\
\hline $21 \mathrm{~b}$ & $51.6 \pm 2.0$ & $64.0 \pm 2.7$ & 0.018 & +24 \\
\hline $21 a$ & $56.8 \pm 2.7$ & $67.8 \pm 3.2$ & 0.05 & +20 \\
\hline 18 infragranular & $53.7 \pm 2.5$ & $60.8 \pm 1.5$ & 0.05 & +13 \\
\hline VLS & $53.9 \pm 3.1$ & $65.8 \pm 3.9$ & 0.08 & +22 \\
\hline 17 infragranular & $54.1 \pm 2.8$ & $60.4 \pm 1.6$ & 0.09 & +12 \\
\hline 17 supragranular & $52.5 \pm 1.9$ & $57.0 \pm 2.2$ & 0.20 & +9 \\
\hline $\mathrm{PS}^{a}$ & $43.3 \pm 2.8$ & $51.0 \pm 5.1$ & 0.26 & +18 \\
\hline $20 b$ & $41.4 \pm 2.4$ & $36.8 \pm 3.3$ & 0.34 & -11 \\
\hline $20 \mathrm{a}$ & $45.3 \pm 2.1$ & $40.4 \pm 3.8$ & 0.36 & -11 \\
\hline $\mathrm{ALLS}^{a}$ & $52.8 \pm 1.2$ & $49.9 \pm 3.4$ & 0.46 & -5 \\
\hline SVA & $50.3 \pm 3.1$ & $47.4 \pm 3.1$ & 0.54 & -6 \\
\hline $\operatorname{AMLS}^{a}$ & $50.9 \pm 1.1$ & $52.6 \pm 2.6$ & 0.57 & +3 \\
\hline 18 supragranular & $54.2 \pm 1.8$ & $56.6 \pm 4.2$ & 0.66 & +4 \\
\hline 19 & $47.2 \pm 1.9$ & $48.8 \pm 3.4$ & 0.72 & +3 \\
\hline $7^{a}$ & $42.3 \pm 3.1$ & $44.5 \pm 9.2$ & 0.83 & +5 \\
\hline DLS & $47.4 \pm 1.4$ & $47.1 \pm 4.6$ & 0.96 & -1 \\
\hline PLLS $^{b}$ & $46.5 \pm 4.7$ & $46.9 \pm 5.9$ & 0.97 & +1 \\
\hline
\end{tabular}

The values of glucose utilization are the means \pm SE. Structures are rank-ordered according to their statistical significance. The number of animals in each group is listed in the parentheses. Group comparisons were made with the Student's $t$ test. Significant increases in glucose utilization occurred in the granular layers (inner portion of layer III and IV) of areas 17 and 18 and in areas 21a, 21b, and PMLS and in the infragranular layers of area 18 in the experimental group compared with the control group. In area VLS and the infragranular layers of area 17, the increases in glucose utilization in the experimental group compared with the control group approached significance.

${ }^{a}$ In the experimental group, $n=3$.

${ }^{b}$ In the control group, $n=2$.

of regions were always labeled in each experimental cat, but the location of the label varied slightly from animal to animal. In addition, there was no increase in metabolic activity at the border between the regions corresponding to areas 21 a and PMLS and between VLS and $21 \mathrm{~b}$, in the fundus of the suprasylvian sulcus in PMLS and in the most rostral portion of area PMLS in the experimental cats compared with the control cats. There was a relatively small increase in metabolic activity, compared with the rest of areas 17 and 18, at the border between areas 17 and 18. The electrophysiologically defined PMLS (Fig. 4C) extends $6 \mathrm{~mm}$ more rostral than did the corresponding region of high metabolic activity ("c" in Fig. 4, $A, B$ ).

\section{Discussion}

The principal conclusion from this study is that there is a 20 $36 \%$ increase in glucose utilization in 5 cortical regions - corresponding to areas $17,18,21 \mathrm{a}, 21 \mathrm{~b}$, and PMLS-in cats gen-

and 18 were based on thionine-stained tissue sections (Otsuka and Hassler, 1962). The boundaries of the other visual cortical areas were based on published electrophysiological mapping studies (Tusa et al., 1981). All of the cortical regions with a relatively high metabolic activity (as indicated by the red color) lie within areas $17,18,21 \mathrm{a}, 21 \mathrm{~b}$, PMLS, and VLS or within a region that corresponds with auditory cortex $(A u)$ (Reale and Imig, 1980). 

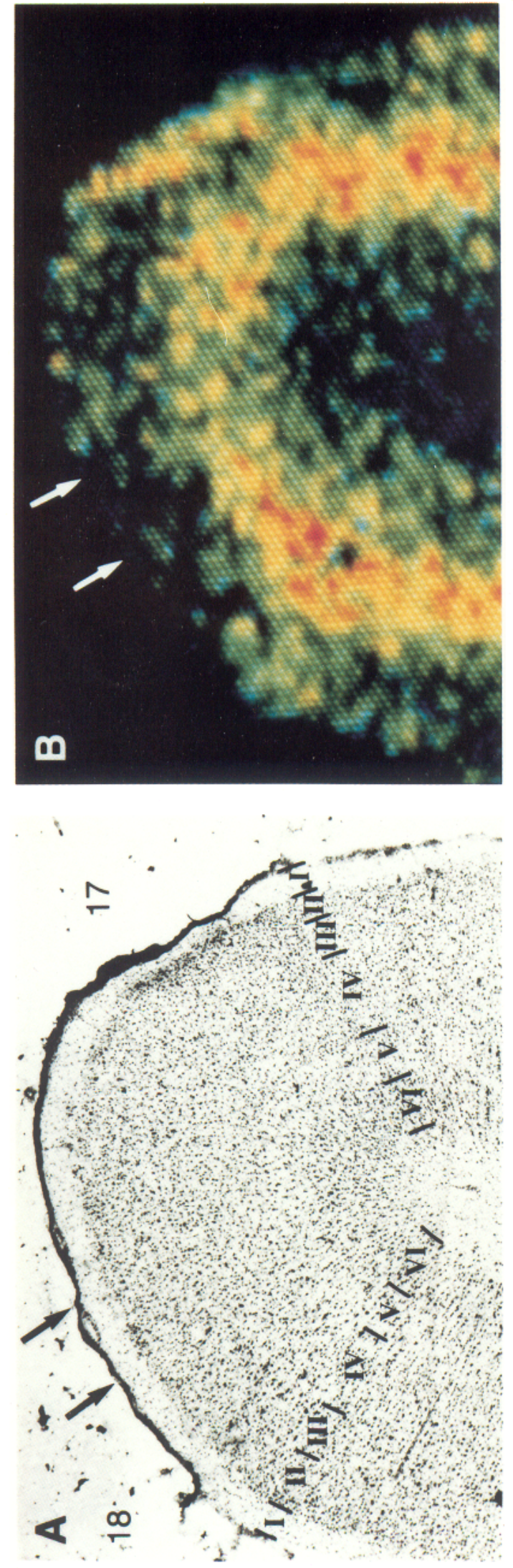

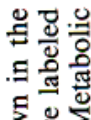

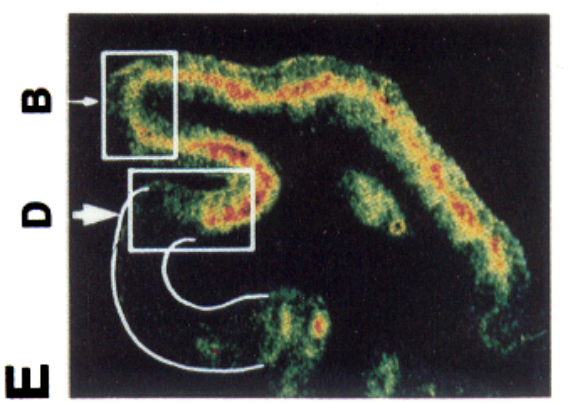

究恼

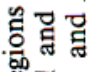

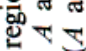

4.5

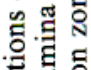

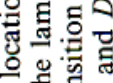

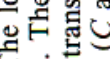

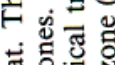

讨

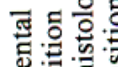

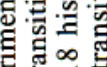

政

s.

可证

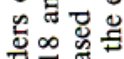

장종

os

군

$\infty$ 论

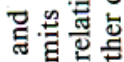

$\infty$.

击要

o

कै

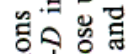

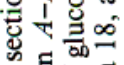

.

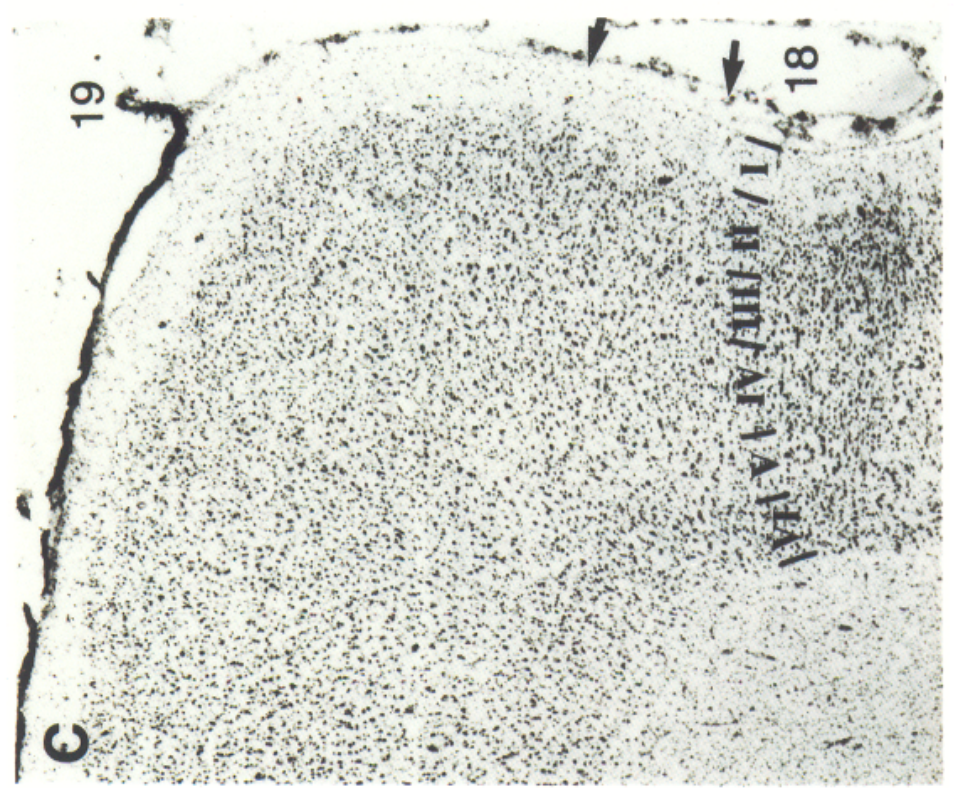

焉言焉

के

항

멍ㅇㅇㅇ

․․응

的的需

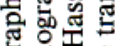

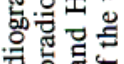

잉

일

o 0 .

ㄷㅇㅇㅇㅛ

彭害

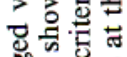

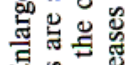

要

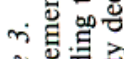

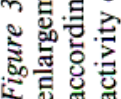


erating horizontal $\mathrm{OKN}$ compared with cats viewing a stationary OKN drum $(p<0.05)$. There was also a $22 \%$ increase in glucose utilization in area VLS in the experimental cats compared with the control cats, but this difference did not reach statistical significance $(p<0.09)$. No significant change in metabolic activity occurred in areas 7, 19, 20a, 20b, AMLS, ALLS, PLLS, DLS, and SVA $(p>0.20)$. When the more rigorous Bonferroni correction for multiple comparisons was applied, only the granular layers of areas 17 and 18 had a truly statistically significant increase in the cxpcrimental group compared with the control group. The Bonferroni correction can conceal physiologically significant changes, however, when the number of subjects studied is small, as in our study. Therefore, our determination of the relevance of an increase in glucose utilization was based on both the percentage change in glucose utilization and on the results of statistical analyses using Student's $t$ test.

The cortical areas in which we found an increase in glucose utilization are part of the region thought to be involved in horizontal OKN based on lesion studies and anatomical projection studies. Bilateral ablation encompassing areas $17-19$ or unilateral ablation encompassing areas 7, AMLS, PMLS, VLS, ALLS, PLLS, and DLS decreases slow phase eye velocity of OKN (Montalaro et al., 1981; Ventre, 1985). A detailed evaluation of the effects of selective ablation within these regions has not been made, however, so it is possible that not all of these areas are involved in OKN. The nucleus of the optic tract (NOT) and the dorsal terminal nucleus (DTN), 2 subcortical regions involved in horizontal OKN, receive projections from areas 17 , 18, 21a, 21b, AMLS, PMLS, and PLLS (Berson and Graybiel, 1980; Schoppmann, 1981; Marcotte and Updyke, 1982). Projections from cortex to these subcortical areas may be involved in functions other than OKN. We believe that the deoxyglucose technique has allowed us to further define the specific cortical areas involved in horizontal OKN. It is possible that metabolic activity in different cortical areas would increase if a vertically moving stimulus were used.

\section{Effect of stimulus direction}

The presence of direction-selective cells in cat cortex has been known for many years (Hubel and Wiesel, 1959, 1962). Although all directions appear to be represented in different cortical areas, single-unit studies in paralyzed cats have shown that not all directions are equally represented. For example, in areas 17 and 18, downward movement is preferred more often than upward movement, and temporal movement is preferred more than movement nasally (Berman et al., 1987). Additionally, in PMLS and PLLS, 3 times as many cells prefer stimuli moving away from the representation of area centralis as prefer stimuli moving toward area centralis (Camarda and Rizzolatti, 1976). Rauschecker et al. (1987) extended these findings to show that the preferred direction for cells in area PMLS was not along the horizontal meridian but, rather, was away from area centralis into the contralateral upper visual field. In our study, however, cats were generating eye movements in both directions along the horizontal meridian. The direction of the stimulus movement across the retina during slow-phase eye movements was in the opposite direction of the stimulus movement across the retina during the quick-phase eye movements. A bias in the directional preference of the cells, therefore, would not be reflected by asymmetries in local rates of glucose utilization.

\section{Laminar distribution of label}

The laminar distribution of metabolic activity in our study is most consistent with the concept that deoxyglucose labeling reflects the metabolic activity of axon terminals (Schwartz et al., 1979; Kadekaro et al., 1985). In areas 17 and 18 in the experimental cats, glucose utilization was most significantly increased in the granular layers (inner part of layer III and in layer IV) and moderately increased in the infragranular layers (layers $\mathrm{V}$ and VI). This pattern of increased metabolic activity coincides with the distribution of projections from the main laminae of the dorsal lateral geniculate nucleus (dLGN), which terminates in the inner part of layer III, layer IV, and layer VI (LeVay and Gilbert, 1976; Ferster and LeVay, 1978: Symonds et al., 1981). Although the C laminae of dLGN and the pulvinar-lateral posterior nuclear complex also project to areas 17 and 18 , these projections terminate, in part, outside of the layers activated in our study (LeVay and Gilbert, 1976; Symonds et al., 1981). Areas 17 and 18 also receive projections from other cortical areas, but the laminar distribution of the projections is not known (Symonds and Rosenquist, 1984).

In areas $21 \mathrm{a}, 21 \mathrm{~b}$, PMLS, and VLS the increase in metabolic activity in the experimental cats was more diffuse and was distributed throughout layers II-V. Within area PMLS this distribution of increased metabolic activity overlaps with the distribution of projections from areas 17 and 18, which terminate in layers III-V (Kawamura and Naito, 1976; Sugiyama, 1979; Kato et al., 1986). Although PMLS also receives projections from subcortical areas, the correlation between subcortical terminals and the laminar distribution of label is not strong. The C lamina of dLGN projects to layers I and IV, and the medial interlaminar nucleus and the posterior nucleus project to layer IV of PMLS (Rosenquist et al., 1974; LeVay and Gilbert, 1976). Areas 21a, $21 \mathrm{~b}$, and VLS also receive projections from areas 17 and 18 and the thalamus (Symonds et al., 1981; Symonds and Rosenquist, 1984), but the laminar distribution of these projections is not known.

Based on preliminary data, the increase in glucose utilization in areas PMLS and 21a in cats generating OKN appears to depend on areas 17 and 18 (Herdman et al., 1987). Following unilateral ablation of areas 17 and 18 plus section of the corpus callosum, areas $21 \mathrm{a}$ and PMLS no longer show an increase in metabolic activity in cats generating OKN. This lack of an increase in metabolic activity may be due to the disruption of the bilateral projections from areas 17 and 18 to areas $21 \mathrm{a}$ and PMLS (Segraves and Rosenquist, 1982; Symonds and Rosenquist, 1984).

In summary, the laminar distribution of increased metabolic activity in cats generating OKN in areas 17 and 18 corresponds most closely to the distribution of the projections from the main laminae of the dIGN. The laminar distribution of increased metabolic activity in area PMLS corresponds best to the distribution of the projections from areas 17 and 18 . Based on the correlation of metabolic activity with the laminar distribution of terminals, the sequence of information processing used during OKN may be from dLGN to areas 17 and 18, and from areas 17 and 18 to PMLS.

\section{Regional distribution of label within areas}

We found that the increase in metabolic activity in cats generating OKN did not occupy the full extent of areas 17, 18, 21 a, 
Figure 4. Two-dimensional reconstruction of cerebral cortex from 2 experimental cats ( $A$ and $B$ ). The portion of cortex with increased metabolic activity in the experimental cats compared with the control cats is shaded. These flat maps can be compared with the 2-dimensional reconstruction of the electrophysiological maps of Tusa et al. (1981) (C). Thin solid lines indicate the contour of the middle of the cortical mantle from coronal sections used in the reconstructions. Thick solid lines indicate the lips of each sulcus, and the dashed lines indicate the fundus of each sulcus. The arrows connecting the ends of some thin solid lines indicate the location of cuts that were made in the contour lines in order to flatten the reconstruction. The thick arrow on the medial view of the hemisphere in $C$ indicates the location of these cuts on the hemisphere. The coronal sections used in the construction of the flat map are indicated on the lateral views of the cat brain. In $C$, the histological border of areas 17 and 18 is indicated by a heavy dotted line. The shaded region labeled $a$ in the reconstructions of metabolic activity corresponds to areas 17 and 18 , $b$ to area $21 \mathrm{a}, c$ to PMLS, $d$ to area $21 \mathrm{~b}$, and $e$ to area VLS. The A/P level for the rostral extent of the label corresponding to area PMLS is indicated on the lateral surface view of the hemisphere. $\Lambda$ bbreviations: $C C$, corpus callosum; $C r$, cruciatus sulcus; $S p$, splenial sulcus; $S s$, suprasplenial sulcus; Lat, lateral sulcus; $P l$, posterior lateral sulcus; Ent, entolateral sulcus; Mss, middle suprasylvian sulcus; $P S S$, posterior suprasylvian sulcus; $P e$, posterior ectosylvian sulcus; $A e$, anterior ectosylvian sulcus; $S y$, sylvian sulcus; $R h$, rhinal sulcus; $E r h$, entorhinal cortex; Pam, paramygdala cortex.
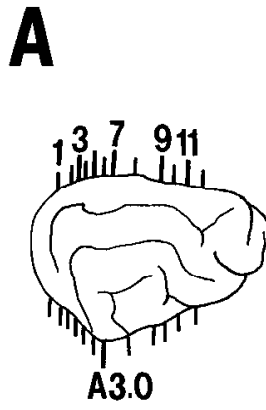
B

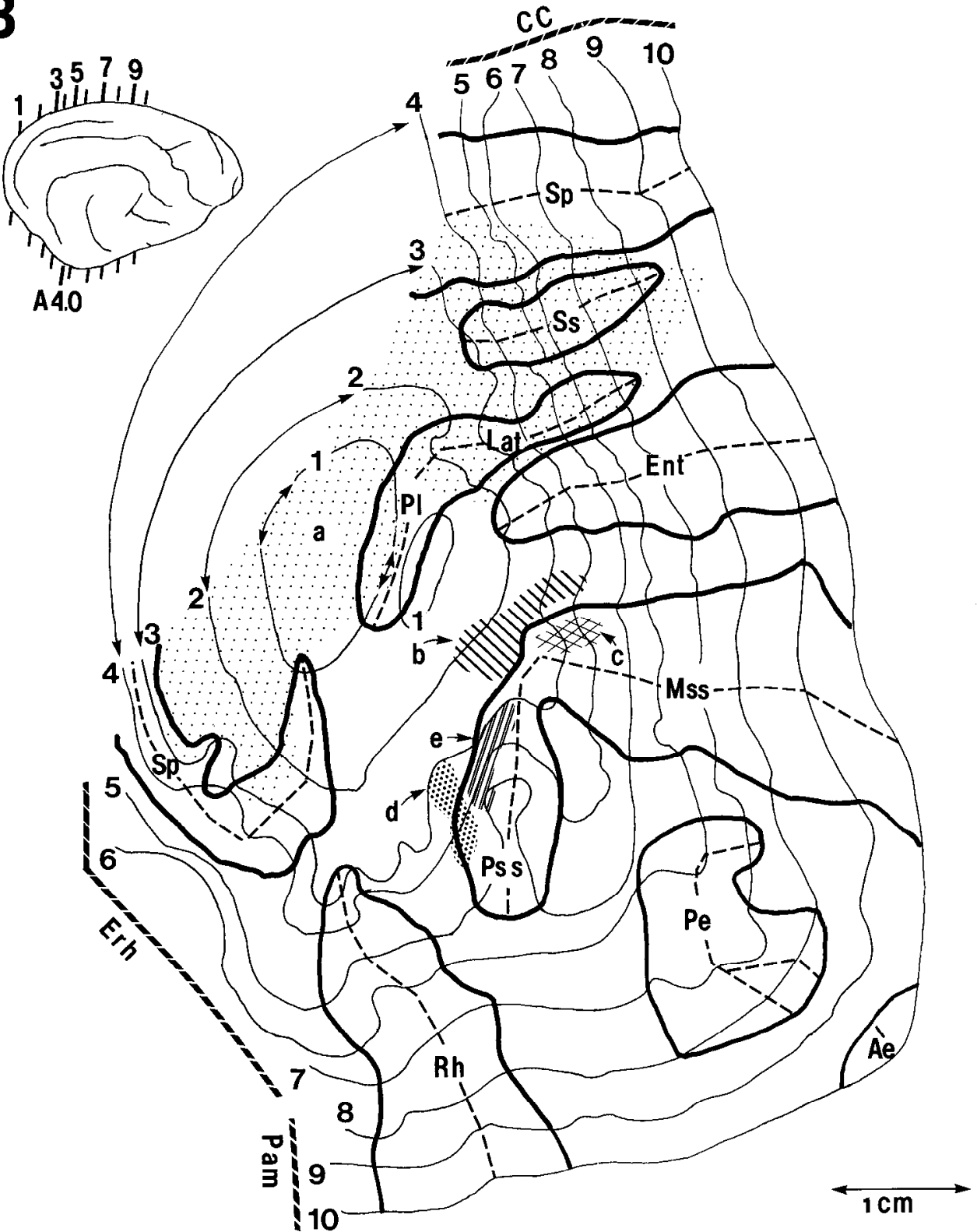

Figure 4. Continued.

the representation of area centralis. Thus, the spatial and temporal frequency of the stimulus we used could explain the regional distribution of label in areas 17, 18, and PMLS. Moreover, we believe the results of our metabolic study extend our knowledge about the regional distribution of preferred spatial frequency throughout areas 17, 18, and PMLS. Previous studies on the distribution of preferred spatial frequencies in these areas were limited to the examination of the more central portions of the visual field (Movshon et al., 1978; Tootell et al., 1981; Morrone et al., 1986; Zumbroich and Blakemore, 1987). Based on our metabolic studies, cells beyond $15^{\circ}$ in areas 17 and 18 appear to respond to a stimulus with a spatial frequency of less than $0.38 \mathrm{cycles} / \mathrm{deg}$. In contrast, cells beyond $50^{\circ}$ in area PMLS do not appear to respond to a stimulus with a spatial frequency range between 0.125 and 0.38 cycles/deg. Further studies are needed to determine the preferred spatial frequencies of the cells in the representation of the more peripheral portions of the visual field.
The major stimulus for generating OKN is retinal-slip velocity. Neurons that encode retinal-slip velocities in the cat have been examined only in area 18 (Hoffman et al., 1984). In this area, cells are tuned to retinal-slip velocities ranging from $2^{\circ}$ to $100 \% \mathrm{sec}$. The average retinal-slip velocities generated during our experiment are within this range $(29 \% \mathrm{sec}$ during slow-phase eye movements and $95 \% \mathrm{sec}$ during quick-phase eye movements). It is not known whether a regional distribution of preferred retinal-slip velocities exists in area 18 , however, a regional distribution of preferred target velocities has been described in paralyzed cats in areas 17, 18, and PMLS. In areas 17 and PMLS, cclls arc best tuncd to a stimulus velocity of less than or equal to $10 \% / \mathrm{sec}$ within the representation of the central portion of the visual field and to higher stimulus velocities in the peripheral portion of the visual field (Wilson and Sherman, 1976; Orban et al., 1985; Rauschecker et al., 1987). The distribution of preferred velocity tuning could explain the relative decrease in metabolic activity in areas 17 and PMLS near the area centralis 


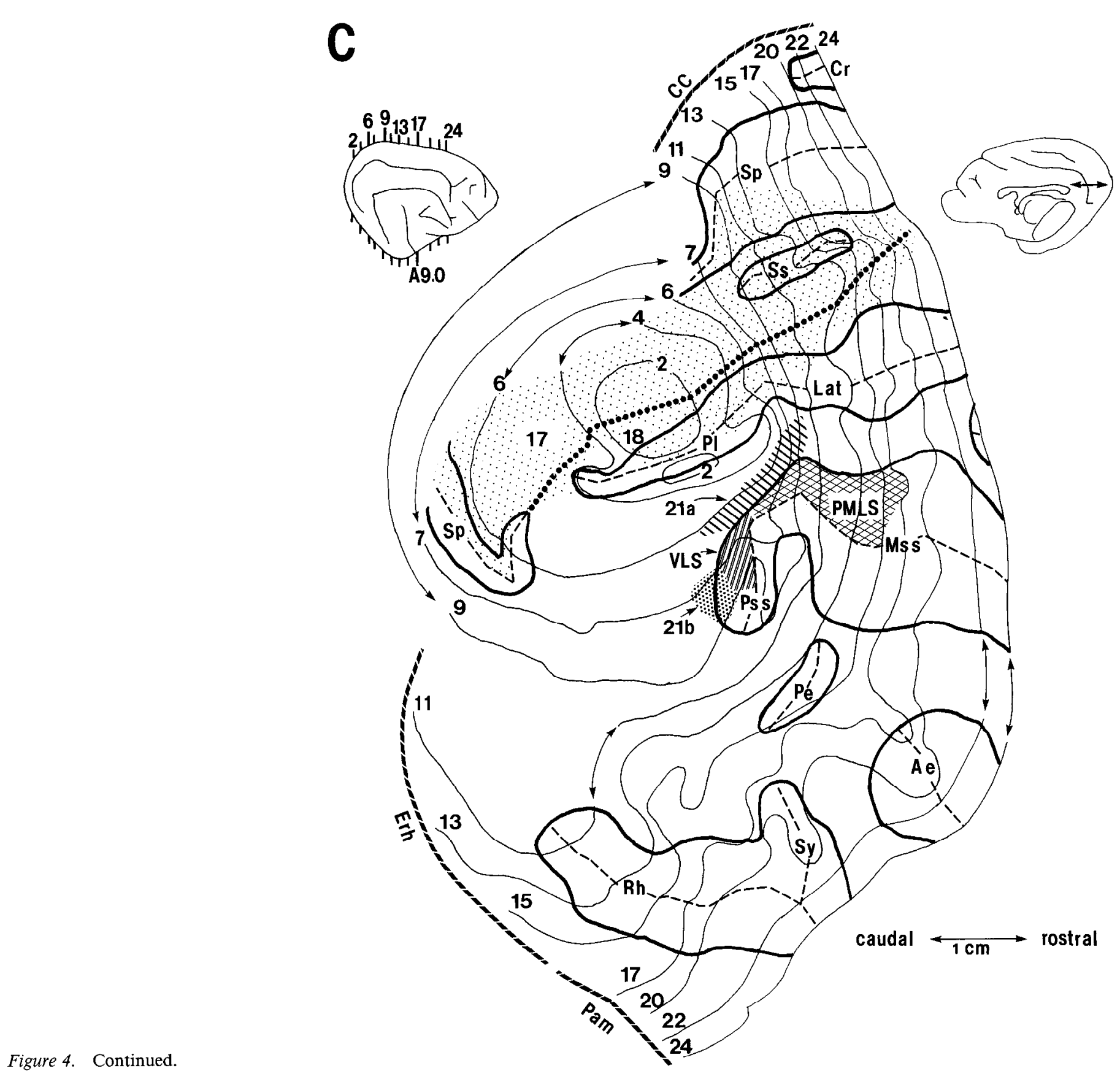

representation in our study. Cells throughout the entire representation of area 18 prefer higher stimulus velocities than cells in area 17 (Orban et al., 1985), and as we found, all of area 18 should be activated by the stimulus we used. Thus, the retinalslip velocity elicited by our stimulus could explain some of the regional distribution of metabolic activity in areas 17,18 , and PMLS in our cats if the regional distribution of retinal-slip velocities in awake, behaving cats is similar to the regional distribution of target velocity tuning in paralyzed cats. Further studies are needed to determine if cells in cat cerebral cortex other than area 18 encode retinal-slip velocity and whether preferred retinal-slip velocities vary with eccentricity.

In summary, the regional distribution of metabolic activity we found in areas 17,18 , and PMLS may be due to the distribution of spatial frequency or possibly retinal-slip velocity or target velocity preferences in these areas. A lower rate of glucose utilization also occurs at the borders of area 21a and PMLS, and areas VLS and $21 \mathrm{~b}$ where the central portion of the visual field is represented. Although spatial frequency and retinal-slip velocity preferences have not been examined in areas $21 \mathrm{a}, 21 \mathrm{~b}$, and VLS using electrophysiological techniques, our study suggests that these parameters may be regionally distributed in these areas as well.

\section{Proprioceptive influences}

Another possible factor contributing to the metabolic activity of cat cortex is the influence of proprioceptive signals from extraocular muscles. It is known, for instance, that $25 \%$ of the cells in area 17 have a reproducible neuronal response to stretch of the extraocular muscles (Buisseret and Maffei, 1977). In our 
study, the control cats made only $1 / 20$ th the number of quick phase eye movements compared with the experimental cats. This may have influenced the relative amount of proprioceptive information received in cortex by the 2 groups, contributing to the difference in metabolic activity. No regional distribution of the cortical cells responding to proprioceptive inputs has been described, however.

\section{Motor and efference copy}

It is unlikcly that a regional distribution of metabolic activity is due to a regional distribution of cells that code a motor command or an efference copy signal during OKN. Of the $70 \%$ of the cells that can be driven during OKN in area 18 in awake, behaving cats, only $1-2 \%$ of the cells respond clearly to eye movements generated in the dark (Hoffmann et al., 1984). Most of the cells in area 18 responding during $\mathrm{OKN}$, therefore, do not appear to be coding a motor command or an efference copy signal. Furthermore, no regional distribution for these cells was described. Although neurophysiological recordings have not been done in other cortical areas during the generation of OKN, recordings have been made during vestibular stimulation. Vanni-Mercier and Magnin (1982) have shown that cells in areas $17(27 \%), 18(24 \%)$, PMLS (12\%), $19(2 \%)$, and $21 \mathrm{a}(2 \%)$ discharge at the end of each quick-phase eye movement produced during vestibular stimulation in the dark. These cells are therefore thought to be coding efference copy of the quick-phase eye movements. No regional distribution has been described for these efference copy signals.

In conclusion, we found that rates of glucose utilization are increased in areas 17, 18,21a, 21b, PMLS, and VLS in cats generating $\mathrm{OKN}$ compared with cats viewing a stationary $\mathrm{OKN}$ drum. In order to determine whether these areas are critically involved in the generation of OKN, we studied the effect of unilateral lesions restricted to these areas. The results of the ablation study are reported in the following paper (Tusa et al., 1989).

\section{References}

Albus, K. (1979) ${ }^{14} \mathrm{C}$-deoxyglucose mapping of orientation subunits in cats visual cortical areas. Exp. Brain Res. 37: 609-613.

Albus, K., and B. Sieber (1984) On the spatial arrangement of iso-orientation bands in the cat's visual cortical areas 17 and 18: $\mathrm{A}{ }^{14} \mathrm{C}$-deoxyglucose study. Exp. Brain Res. 56: 384-388.

Berman, N. E. J., M. E. Wilkes, and B. R. Payne (1987) Organization of orientation and direction selectivity in arcas 17 and 18 of cat cerebral cortex. J. Neurophysiol. 58: 676-699.

Berson, D. M., and A. M. Graybiel (1980) Some cortical and subcortical fiber projections to the accessory optic nuclei in the cat. Neuroscience 5: 2203-2217.

Buisseret, P., and L. Maffei (1977) Extraocular proprioceptive projections to visual cortex. Exp. Brain Res. 28: 421-425.

Camarda, R., and G. Rizzolatti (1976) Visual receptive fields in the lateral suprasylvian area (Clare-Bishop Area) of the cat. Brain Res. 101: 427-443.

Ferster, D., and S. LeVay (1978) The axonal arborizations of lateral geniculate neurons in the striate cortex of the cat. J. Comp. Neurol. 182: 923-944.

Flood, D. G., and P. D. Coleman (1979) Demonstration of orientation columns with $\left[{ }^{14} \mathrm{C}\right] 2$-deoxyglucosc in a cat rearcd in a striped environment. Brain Res. 173: 538-542.

Goochee, C., W. Rasband, and L. Sokoloff (1980) Computerized densitometry and color coding of $\left[{ }^{14} \mathrm{C}\right]$ deoxyglucose autoradiographs. Ann. Neurol. 7: 359-370.

Hand, P. J. (1981) In Neuroanatomical Tract-Tracing Methods, L. Heimer and M. J. Robards, eds., pp. 511-538, Plenum, New York.

Herdman, S. J., and R. J. Tusa (1984) Local cerebral glucose utilization in cortex of awake, behaving cat in response to an optokinetic stimulus. Soc. Neurosci. Abstr. 10:933.

Herdman, S. J., and R. J. Tusa (1986) The role of striate cortex in the generation of optokinetic nystagmus. Physical Ther. 66: 742.

Herdman, S. J., R. J. Tusa, and C. B. Smith (1987) Areas 17 and 18 contribute the major functional input to two suprasylvian cortical areas in the cat during generation of optokinetic nystagmus. Soc. Neurosci. Abstr. 13: 1625.

Hoffman, K.-P. (1982) Cortical versus subcortical contributions to the optokinetic reflex in the cat. In Functional Basis of Ocular Motility Disorders, G. Lennerstrand, D. S. Zee, and E. L. Keller, eds., pp. 303310, Pergamon, Oxford, UK.

Hoffman, K.-P., R. Bauer, H. P. Huber, and M. Mayr (1984) Single cell activity in area 18 of the cat's visual cortex during optokinetic nystagmus. Exp. Brain Res. 57: 118-127.

Hubel, D. H., and T. N. Wiesel (1959) Receptive fields of single neurons in cat's striate cortex. J. Physiol. (Lond.) 148: 574-591.

Hubel, D. H., and T. N. Wiesel (1962) Receptive fields, binocular interaction and functional architecture in cat's visual cortex. J. Physiol. (Lond.) 160: 106-154.

Humphrey, A. L., M. Sur, D. J. Uhlrich, and S. M. Sherman (1985a) Projection patterns of individual X-and Y-cell axons from the lateral geniculate nucleus to cortical area 17 in the cat. J. Comp. Neurol. 233: 159-189.

Humphrey, A. L., M. Sur, D. J. Uhlrich, and S. M. Sherman (1985b) Termination patterns of individual $\mathrm{X}$ - and $\mathrm{Y}$-cell axons in the visual cortex of the cat: Projections to area 18, to the $17 / 18$ border region, and to both areas 17 and 18. J. Comp. Neurol. 233: 190-212.

Kadekaro, M., A. Crane, and L. Sokoloff (1985) Differential effects of electrical stimulation of sciatic nerve on metabolic activity in spinal cord and dorsal root ganglion in the rat. Proc. Natl. Acad. Sci. USA 82: 6010-6013.

Kato, N., S. Kawaguchi, and H. Miyata (1986) Postnatal development of afferent projections to the lateral suprasylvian visual area in the cat: An HRP study. J. Comp. Neurol. 252: 543-554.

Kawamura, K., and J. Naito (1976) Corticocortical afferents to the cortex of the middle suprasylvian sulcus area in the cat. Exp. Brain Res. (Suppl.) 1: 323-328.

Lang, W., and V. Henn (1980) Columnar pattern in the cat's visual cortex after optokinetic stimulation. Brain Rcs. 182: 446-450.

LeVay, S., and C. D. Gilbert (1976) Laminar patterns of geniculocortical projection in the cat. Brain Res. 113: 1-19.

Lowel, S., B. Freeman, and W. Singer (1987) Topographic organization of the orientation column system in large flat-mounts of the cat visual cortex: A 2-deoxyglucose study. J. Comp. Neurol. 255: 401-415.

Marcotte, R. R., and B. V. Updyke (1982) Cortical visual areas of the cat project differentially onto the nuclei of the accessory optic system. Brain Res. 242: 205-217.

Miller, R. G. (1966) Simultaneous Statistical Inference, pp. 67-70, McGraw-Hill, New York.

Montarolo, P. G., W. Precht, and P. Strata (1981) Functional organization of the mechanisms subserving the optokinetic nystagmus in the cat. Neuroscience 6: 231-246.

Morronc, M. C., M. Di Stcfano, and D. C. Burr (1986) Spatial and temporal properties of neurons of the lateral suprasylvian cortex of the cat. J. Neurophysiol. 56: 969-986.

Movshon, J. A., I. D. Thompson, and D. J. Tolhurst (1978) Spatial and temporal contrast sensitivity in areas 17 and 18 of the cat visual cortex. J. Physiol. (Lond.) 283: 101-120.

Orban, G. A., K.-P. Hoffmann, and J. Duysens (1985) Velocity selectivity in the cat visual system. I. Responses of LGN cells to moving bar stimuli: A comparison with cortical areas 17 and 18. J. Neurophysiol. 54: 1026-1049.

Otsuka, R., and R. Hassler (1962) Uber aufbau und gliederung der corticalen sehsphare bei der katze. Archiv. Psychol. Zeitschr. 203: 212-234.

Palmer, L. A., A. C. Rosenquist, and R. J. Tusa (1978) The retinotopic organization of the latcral suprasylvian areas in the cat. J. Comp. Neurol. 177: 237-256.

Rauschecker, J. P., M. W. von Grunau, and C. Poulin (1987) Centrifugal organization of direction preference in the cat's lateral suprasylvian visual cortex and its relation to flow field processing. J. Neurosci. 7: 943-958.

Reale, R. A., and T. J. Imig (1980) Tonotopic organization in auditory cortex of the cat. J. Comp. Neurol. 192: 265-291. 
Robinsun, D. A. (1963) A method of measuring eye movement using a scleral search coil in a magnetic field. IEEE Trans. Biomed. Eng. 26: $137-145$.

Robinson, D. A. (1976) Adaptive gain control of vestibuloocular reflex by the cerebellum. J. Neurophysiol. 39: 954-969.

Rosenquist, A. C. (1985) Connections of visual cortical areas in the cat. In Cerebral Cortex, A. Peters and E. G. Jones, eds., pp. 81-117, Plenum, New York.

Rosenquist, A. C., S. B. Fdwards, and L. A. Palmer (1974) An autoradiographic study of the projections of the dorsal lateral geniculate nucleus and the posterior nucleus in the cat. Brain Res. 80:71-93.

Schoppmann, A. (1981) Projections from areas 17 and 18 of the visual cortex to the nucleus of the optic tract. Brain Res. 223: 1-17.

Schoppmann, A., and M. P. Stryker (1981) Physiological evidence that the 2-deoxyglucose method reveals orientation columns in cat visual cortex. Nature 293: 574-576.

Schwartz, W. J., C. B. Smith, L. Davidsen, H. Savaki, L. Sokoloff, M. Mata, D. J. Fink, and H. Gainer (1979) Metabolic mapping of functional activity in the hypothalamoneurohypophysial system of the rat. Science 205: 723-725.

Segraves, M. A., and A. C. Rosenquist (1982) The afferent and efferent callosal connections of retinotopically defined areas in cat cortex. J. Neurosci. 2: 1090-1107.

Singer, W. (1981) Topographic organization of orientation columns in the cat visual cortex. Exp. Brain Res. 44: 431-436.

Smith, C. B. (1983) In Current Methods in Cellular Neurobiology, Vol. 1, J. L. Barker and J. F. McElvey, eds., pp. 269-317, Wiley, New York.

Sokoloff, L. (1982) The radioactive deox yglucose method. In Advances in Neurochemistry, B. W. Agranoff and M. H. Aprison, eds., Plenum, New York.

Sokoloff, L., M. Reivich, C. Kennedy, M. H. Des Rosiers, C. S. Patlak, K. D. Pettigrew, O. Sakadura, and M. Shinohara (1977) The $\left[{ }^{4} \mathrm{C}\right]$ deoxyglucose method for the measurement of local cerebral glucose utilization: Theory, procedure, and normal values in the conscious and anesthetized albino rat. J. Neurochem. 28: 897-916.

Strong, N. P., R. Malach, P. I ee, and R. C. Sluyters (1984) Horizontal optokinetic nystagmus in the cat: Recovery from cortical lesions. Dev. Brain Res. 13: 179-192.

Sugiyama, M. (1979) The projection of the visual cortex on the ClareBishop area in the cat. A degenerative study with the electron microscope. Exp. Brain Res. 36: 433-443.

Symonds, L. L., and A. C. Rosenquist (1984) Corticocortical connec- tions anong visual areas in the cat. J. Comp. Neutol. 229: 1-38.

Symonds, L. L., A. C. Rosenquist, S. B. Edwards, and L. A. Palmer (1981) Projections of the pulvinar-lateral posterior complex to visual cortical areas in the cat. Neuroscience $6: 1995-2020$.

Thompson, I. D., M. Kossut, and C. Blakemore (1983) Development of orientation columns in cat striate cortex revealed by 2-deoxyglucose autoradiography. Nature 301: 712-715.

Tootell, R. B., M. S. Silverman, and R. L. De Valois (1981) Spatial frequency columns in primary visual cortex. Science 214: 813-815.

Tusa, R. J., and L. A. Palmer (1980) Retinotopic organization of area 20 and 21 in the cat. J. Comp. Neurol. 193: 147-164.

Tusa, R. J., L. A. Palmer, and A. C. Rosenquist (1978) The retinotopic organization of area 17 (striate cortex) in the cat. J. Comp. Neurol. 177: 213-236.

Tusa, R. J., A. C. Rosenquist, and L. A. Palmer (1979) Retinotopic organization of areas 18 and 19 in the cat. J. Comp. Neurol. 185: $657-678$.

Tusa, R. J., L. A. Palmer, and A. C. Rosenquist (1981) Multiple cortical visual areas: Visual field topography in the cat. In Cortical Sensory Organization, Vol. 2, C. N. Woolsey, ed., Humana, Clifton, NJ.

Tusa, R. J., J. L. Demer, and S. J. Herdman (1989) Cortical areas involved in OKN and VOR in cats: Cortical lesions. J. Neurosci. 9: 1163-1178.

Ungerleider, L. G., and R. Desimone (1986) Cortical connections of visual area MT in the Macaque. J. Comp. Neurol. 248: 190-222.

Van Essen, D. C., and J. H. R. Maunsell (1980) Two-dimensional maps of the cerebral cortex. J. Comp. Neurol. 191: 255-281.

Vanni-Mercier, G., and M. Magnin (1982) Retinotopic organization of extra-retinal saccade-related input to the visual cortex in the cat Exp. Brain Res. 46: 368-376.

Ventre, J. (1985) Cortical control of oculomotor functions. I. Optokinetic nystagmus. Behav. Brain Res. 15: 211-226.

Wagner, H.-J., K.-P. Hoffmann, and H. Zwerger (1981) Layer-specific labelling of cat visual cortex after stimulation with visual noise: $A$

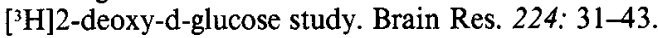

Wilson, J. R., and S. M. Sherman (1976) Receptive-field characteristics of neurons in cat striate cortex: Changes with visual field eccentricity. J. Neurophysiol. 39: 512-533.

Zumbroich, T. J., and C. Blakemore (1987) Spatial and temporal frequency in the suprasylvian visual cortex of the cat. J. Neurosci. 7: 482-500. 